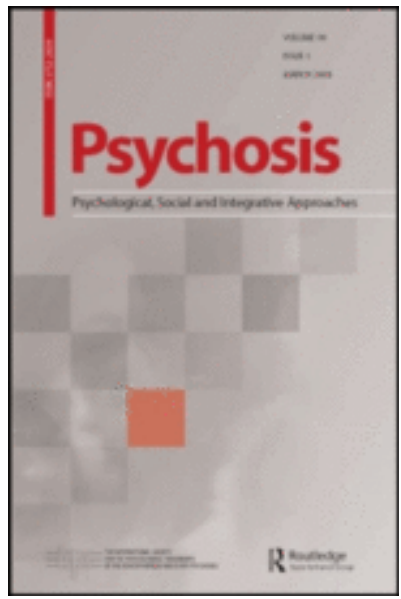

\title{
Comparisons and associations between personality, creative potential and achievement in creative, non-creative and early psychosis group participants
}

\begin{tabular}{|r|l|}
\hline Journal: & Psychosis \\
\hline Manuscript ID & RPSY-2018-0069.R1 \\
\hline Kanuscript Type: & Research Article \\
\hline Keywords: & Creativity, Early psychosis, Personality, Schizotypy \\
\hline & $\begin{array}{l}\text { Epidemiological evidence supports common genetic determinants } \\
\text { between psychosis spectrum populations and creative individuals. } \\
\text { Aspects of personality may contribute to protecting the creative artist } \\
\text { from psychosis vulnerability. This study examines the similarities and } \\
\text { differences in personality within a sample of Early Psychosis (EP), } \\
\text { Creative Control (CC) and Non-Creative Control (NCC) participants. } \\
\text { Findings indicated that the CC group shared closer personality } \\
\text { commonalities with the EP group than with NCC participants, on traits } \\
\text { such as Neuroticism, Openness, and Impulsive Non-conformity as well as } \\
\text { on variables such as Unusual Experiences, Cognitive Disorganisation and } \\
\text { Paranoia/Suspiciousness. However, the CC group may better manage } \\
\text { their emotional sensitivity and interpersonal suspiciousness than the EP } \\
\text { participants. In separate analyses, CC and EP participants recorded } \\
\text { higher creative cognition than NCC participants. Unsurprisingly the CC } \\
\text { group reported significantly higher creative achievement than the EP and } \\
\text { NCC samples. Of note, the findings indicate that, EP participants } \\
\text { recorded significantly higher creative achievement than NCC, suggesting } \\
\text { that EP patients demonstrate some capacity for creative cognition and } \\
\text { creative achievement. These preliminary findings may encourage further } \\
\text { research and promote avenues of treatment for at risk creative } \\
\text { individuals and early psychosis individuals. }\end{array}$ \\
\hline
\end{tabular}




\section{SCHOLARONE ${ }^{\mathrm{m}}$ Manuscripts}




\section{Introduction}

2 Similarities between highly creative individuals and those with bipolar disorder and

3 schizophrenia have been well documented (Andreasen, 1987; Brod, 1997; Jamison, 1995; Ma,

4 2009; Rybakowski, Klonowska, Parrzala, \& Jaracz, 2008), however there is ongoing debate over

5 what aspects of these schizophrenia and bipolar disorder populations contribute to this

6 association. Three large Swedish epidemiological studies provide support for the assertion that

7 there are common genetic determinants between bipolar disorder and schizophrenia (Kyaga et

8 al., 2011; Lichtenstein et al., 2009; MacCabe et al., 2018), and that creativity and creative

9 professions are overly represented amongst those with bipolar disorder and among the family

10 members of those with schizophrenia and bipolar disorder (Kyaga et al., 2011). Furthermore, a

11 recent study also found common polygenetic risk scores between creativity and those with

12 bipolar disorder and schizophrenia (Power et al., 2015) providing additional genetic evidence

13 supporting the association between creativity and mental illness.

15 In considering these associations, a unitary psychosis theory has been proposed (Carson, 2011;

16 Claridge \& Blakey, 2009; Sass, 2001) which argues that the apparently distinct clinical

17 classifications with bipolar disorder and schizophrenia in fact have common underlying

18 processes that differentially contribute to creativity. Specifically, Carson proposed a model of

19 shared vulnerability between those with high creativity and individuals with psychopathology

20 (Carson, 2011) based on existing research into molecular biology. The author suggested that

21 hyper-connectivity, or the unusual neural linking of uncommon brain areas (often associated

22 with psychosis), a preference for novelty, and attenuated latent inhibitions, are shared

23 vulnerability factors operating below the level of consciousness between those with high

24 creativity and those with psychopathology. High IQ, working memory skills and cognitive 
1 flexibility are thought to help protect the high creativity population from developing psychosis

2 by providing a meta-cognitive control over bizarre, unusual thoughts. In contrast, she suggests

3 risk factors such as low IQ, perseveration, and poor working memory may render the creative

4 individual vulnerable to developing psychopathology. Carson acknowledges that this is an

5 incomplete list and suggests additional studies would extend this model. Further clarification is

6 particularly apt as the factors proposed are generic and too broad to have specific clinical

7 application. Since this model was proposed, vulnerability factors for those at risk for psychosis

8 has been an area under increasing investigation (Fusar-Poli et al.), with risk factors such as

9 childhood trauma, early adolescent low functioning and socio-demographic factors along with

10 cognitive deficits such as verbal learning impairments (Carrión et al., 2018) also associated with

11 transition to psychosis. However, these additional vulnerability factors have not, as yet, been

12 considered in relation to a specific creative population.

14 Carson's shared vulnerability model proposed novelty seeking as the only personality trait

15 common to the creative individual and those with psychopathology. This study will examine if

16 aspects of personality beyond the factor outlined by Carson, contribute to "protecting" the

17 creative population from psychosis. Specifically, do aspects of personality and schizotypy

18 differentiate the highly creative from those with expressed psychosis? Schizotypy is considered

19 to be an aggregate of personality traits that lie along a continuum from normality to

20 schizophrenia (Cochrane, Petch, \& Pickering, 2012) (Siddi, Petretto, \& Preti, 2017). Genetic,

21 cognitive and brain fMRI studies provide supportive evidence for an overlap between

22 schizophrenia and schizotypy (Wang et al., 2017). Aspects of positive schizotypy such as

23 Impulsive Non-Conformity and Unusual Experiences, along with personality features such as 
1 Openness and Neuroticism have consistently been associated with both the highly creative,

2 bipolar and schizotypal populations (Batey \& Furnham, 2008; Srivastava et al., 2010).

4 The authors, Nelson and Rawlings (2010) investigated psychopathology and personality

5 indicators of creative experience in a study of 100 creative artists. Aspects of positive

6 schizotypy (Unusual Experiences) were found to be the strongest predictor of creative

7 experience, along with the 'Big Five' personality dimensions of Openness to Experience and

8 Neuroticism, when compared to normative data. This is consistent with a number of other studies

9 associating in particular Openness to Experience with creative cognition (Jung, Grazioplene,

10 Caprihan, Chavez, \& Haier, 2010; Jung, Mead, Carrasco, \& Flores, 2013). As it has been

11 postulated, Openness provides creative individuals with a deeper memory bank of experiences,

12 thoughts and problem solving strategies for creative thinking (Ma, 2009).

14 Whilst the research discussed above has primarily investigated personality in non-clinical

15 populations, a small number of studies have analysed personality and cognitive features in

16 clinical and creative samples. In a comparison of personality similarities and differences between

17 participants with a diagnosis of Bipolar 1 Disorder (BD), unipolar depression diagnosis (MDD),

18 creative arts students (CC) and healthy controls (HC), Nowakowska and colleagues

19 (Nowakowska, Strong, Santosa, Wang, \& Ketter, 2005) reported the most prominent personality

20 similarities were between $\mathrm{BD}$ and $\mathrm{CC}$ populations. In particular the authors found novelty

21 seeking, self-transcendence (the experience of oneself as an integral part of the universe

22 (Cloninger, 1994)) and the affective temperament factor, cyclothymia were similar across BP

23 and CC populations. This finding of common personality traits between Bipolar (BD) and

24 Creative (CC) populations has been supported in two similar studies (Srivastava et al., 2010; 
1 Strong et al., 2007). Both these studies record similarly high scores on Neuroticism and

2 Openness in BD and CC populations, which Strong suggests implicates an affective (e.g.

3 Neuroticism) and cognitive/flexibility (e.g. Openness) component to creativity. Strong et al.

4 (2007) hypothesised that these tendencies may assist creative expression through the ability to

5 tolerate intense and often negative and varied shifts in emotion (Neuroticism), associated with

6 driving innovation through dissatisfaction with the status quo (Strong et al., 2007). In contrast,

7 she suggests Openness (which she associates with cognitive flexibility) may contribute to

8 creative achievement and interpersonal relationships.

10 Taken together, these studies suggest that particular personality traits and certain positive

11 schizotypal traits may differentially contribute to creative cognition. Mason's review of the

12 assessment of schizotypy (Mason, 2015), noted that research into schizotypal personality

13 characteristics should include a measure of paranoia/suspiciousness. Paranoid ideation has also

14 been associated with those at risk for psychosis (Masillo et al., 2017; Valmaggia et al., 2015)

15 however most research has examined the relationship between positive schizotypy and creativity

16 (eg (Nettle, 2006) rather than paranoia. .

18 Similarly, while many studies have researched creative inclination and creative potential with

19 both bipolar and schizophrenia populations (Wang et al., 2017), few studies have investigated

20 creative production or the ability to follow through with creative inclination to actually produce

21 and deliver creative outputs (Andreasen, 1987). Further investigation is warranted into which

22 aspects of personality and schizotypy (including paranoia/suspiciousness) are associated with

23 creative production (or the lack of it) in populations with these clinical disorders, in the presence

24 of creative cognition (Kyaga et al., 2011). 
2 Therefore, the aim of the present study is to further investigate relationships between personality

3 and creativity across clinical, creative and non-creative control samples. Based on previous

4 research, we hypothesise:

5
(1) Non-significant differences in specific personality traits will be observed between highly creative and clinical populations, such that individuals with early psychosis (EP) will report similar levels of Neuroticism and Openness, Impulsive Nonconformity and Unusual Experiences to individuals defined as highly creative; however both groups will show significantly elevated levels of these traits compared to non-creative control individuals.

(2) Personality traits such as paranoia and suspiciousness will be more evident in early psychosis (EP) participants when compared to CC and NCC individuals.

(3) The CC and early psychosis (EP) participants will demonstrate significantly higher creative thinking scores compared to NCC participants, but CC participants will record significantly higher levels of creative achievement when compared to both NCC and EP individuals.

\section{Methods}

Recruitment and study procedures were approved by the Human Research Ethics Committees of the University of New South Wales (HREC UNSW Protocol No. 11279) and ratified by the University of Technology (HREC UTS ETH16-0532). All participants provided written consent prior to participation. Participants were aged $18-35$ as we were interested in first episode psychosis and epidemiological studies suggest the age of onset of psychosis ranges from $15-35$ 
1 with the median age of initial presentation in the mid twenties (Kessler et al., 2007). All

2 participants were given a \$AUD40 monetary reimbursement for travel costs.

3 4

\section{Creative control participants (CC) $N=55$}

25 Creative control participants were recruited following a brief presentation by the lead researcher

26 (JC), to several Creative Art Colleges around Sydney, Australia. The recruitment sites included

27 tertiary creative training institutions such as music colleges (contemporary, classical music, 
1 composition, vocals), visual arts colleges, as well as advertising on relevant creative websites

2 (e.g. livingwithacreativemind.com). Individuals were presented with an outline of the research

3 and gave written consent to take part in the study. Creative controls were screened for past or

4 present psychotic symptoms using a MINI (brief structured psychiatric questionnaire) (Lecrubier

5 et al.). None were found to have past or present syndromal psychiatric disorders. Of those

6 recruited 27 were primarily engaged with music; 15 were visual or graphic artists, 12 were actors

7 or involved in the theatre and 1 was engaged in web development and design.

$9 \quad$ Non-creative control participants (NCC) $N=24$

10 Healthy, non-creative controls were recruited via a university website. The online information

11 asked for psychologically healthy volunteers to participate in research into creative cognition,

12 and thirty-three individuals initially responded. Nine participants were excluded because they

13 met either of the following three exclusion criteria: i) no personal or family history of mental

14 illness; ii) an inability to communicate proficiently in spoken and written English and iii) receipt

15 of more than rudimentary training in any field of creative arts. Using the MINI (Lecrubier et al.),

16 the normal non-creative controls were also screened for any current mental illness and one

17 participant was excluded (eating disorder). These participants were reimbursed for their time.

19 Measures

20 All participants completed a series of tests including self-report questionnaires, mood assessment 21 and intellectual ability testing.

23 Weschler Abbreviated Scale of Intelligence (WASI) (Wechsler \& Zhou, 2011) 
1 In order to screen for IQ, the two-scale version of the WASI was administered to all participants.

2 The WASI has been found to be a brief but valid measure of intelligence in both healthy adult

3 and clinical populations (Ryan et al., 2003). The two-scale version comprises a forty-two item

4 test of vocabulary and a thirty-five item matrix reasoning test. The measure was administered

5 and scored according to standard protocols.

7 Abbreviated Torrance Test for Adults (Goff \& Torrance, 2002).

8 All participants were administered the Abbreviated Torrance Test for Adults (ATTA)(Goff \&

9 Torrance, 2002). This test comprises three tasks where participants are asked to respond to each

10 challenge using imagination and problem-solving ability. The measure was selected as

11 longitudinal studies support the consistent relationship between test behaviour and creative

12 achievement and the Torrance test is the most widely used and well researched creativity

13 measure (Torrance, 2000). Two scorers (JC and SG) evaluated each ATTA and where scores

14 differed, the average was used.

16 Creative Achievement Questionnaire (Carson, 2005).

17 To evaluate creative output, the Creative Achievement Questionnaire (CAQ) (Carson, Peterson,

18 \& Higgins, 2005); was administered to all participants. In the CAQ participants were asked to

19 indicate their creative accomplishments in ten separate domains: (visual arts; music including

20 both instrument and voice; dance; theatre, film and including acting and creative direction;

21 architecture including graphic design; creative writing; humour; inventions including computer

22 and web design). Weighted scores indicating the achievements within each domain were

23 calculated. 
1 Neuroticism Extraversion and Openness Scale Five Factor Inventory (NEO-FFI-R) (McCrae \&

2 Costa, 2004).

3 Participants were administered a self-report personality measure NEO-FFI-R (Costa \& McCrae,

4 1985; Mc Crae \& Costa, 2004) which rates five aspects of personality, namely Neuroticism,

5 Extroversion, Openness, Agreeableness and Conscientiousness. The NEO-FFI-R is a 60 -item,

6 widely used measure of personality.

7

8 Oxford-Liverpool Inventory of Feelings and Experiences (O-LIFE)(Mason \& Claridge, 2006)

9 The Oxford-Liverpool Inventory of Feelings and Experiences (Mason \& Claridge, 2006) is a

10 well used measure of schizotypal personality in schizophrenic patients and healthy controls $(\alpha=$

11 .87) (Ando, Claridge, \& Clark, 2014; Burch, Pavelis, Hemsley, \& Corr, 2006; Cochrane, Petch,

12 \& Pickering, 2010; Yaghoubi H \& A., 2012). It comprises 104 items across four scales; Unusual

13 Experiences (Un Ex), which describes perceptual aberrations and magical thinking and is linked

14 to positive aspects of schizotypy; Impulsive Non-Conformity (ImpNon) describes eccentric

15 forms of behaviour including impulsivity and a lack of self-control; Introverted Anhedonia

16 (InAn) associated with avoidance of intimacy and discomfort in social and physical

17 environments and is associated with negative schizotypy; and Cognitive Disorganisation

18 (CogDis) which contains items describing thought disorder and poor decision making along with

19 aspects of social anxiety.

21 Paranoid Suspiciousness Questionnaire (PSQ) (Rawlings \& Freeman, 1996)

22 The `Paranoia/Suspiciousness Questionnaire was designed to support the O-LIFE as a measure

23 of schizotypy in largely non-clinical populations. It is a 47 -item questionnaire specifically

24 assessing cognitions involving paranoia and suspiciousness. It also includes seven subscales: 
1 interpersonal suspiciousness/hostility (IS); negative affect/withdrawal (NA); anger/impulsiveness

2 (AI); mistrust/wariness (MW) and perceived hardship (PH) (Rawlings \& Freeman, 1997). 3

\section{$4 \quad$ Procedures}

5 All participants were tested individually, at a single session, in a dedicated confidential space

6 either within a hospital environment (EP) or on student campus at a creative arts (CC) or a

7 university setting (NCC). Participants presented themselves at the testing room and completed a

8 written consent form prior to testing. The testing period ranged from 2-3 hours. Standardised test

9 administration protocols were followed for all tests including the two-scale version WASI IQ

10 (Wechsler \& Zhou, 2011). Multiple test administrators were used and all were professionally

11 trained in standardised intelligence testing.

\section{Data analysis}

14 Data were initially screened for missing values, and less than $5 \%$ of the dataset found to be 15 missing which is within recommended limits for non-correction (Tabachnick, Fidell, \&

16 Osterlind, 2001). A series of data normality of distribution checks were then run (presence of

17 outliers, skewness/kurtosis), as well as Levene's test for homogeneity of variance, and all

18 variables found to meet criteria for parametric statistical analyses. A post-hoc power calculation

19 was carried out using G*Power (Erdfelder, Faul, \& Buchner, 1996), which confirmed that

20 assuming a small to medium effect size (0.4), and using an alpha rate of 0.05 , the study was

21 powered at 0.9 to detect a significant difference between groups with the present sample. A

22 Bonferroni correction was applied to all comparative analyses, given the multiple tests conducted

23 in this study. All statistical analyses were conducted using SPSS version 23. 


\section{$1 \quad$ Results}

2

3 Descriptive statistics

4 A total of 100 participants took part in the study (EP: 21; CC: 55; NCC: 24). Mantel-Haenszel

5 chi-square tests of significance were used to test for differences in the bivariate associations

6 between demographic variables (age, sex and IQ), and are presented in Table 1. There were no

7 significant differences in age, gender or IQ between the three groups of participants. The sample

8 was predominantly female $(61.4 \%)$, the mean age of the participants was $23.71(\mathrm{SD}=4.19$;

9 Median $=23$ ), and $53.5 \%$ of all participants were in the younger age group $(<23$ years $)$.

[Insert Table 1 near here]

13 Hypothesis 1:_Non-significant differences in specific personality traits will be observed between

14 highly creative and clinical populations, such that individuals with EP will report similar levels

15 of Neuroticism and Openness, Impulsive Nonconformity and Unusual Experiences to individuals

16 defined as highly creative; however both groups will show significantly elevated levels of these

17 traits compared to non-creative control individuals.

19 Group differences on NEO-FFI-R

20 Group means and standard deviations for NEO results are summarized in Table 2. To examine

21 group differences, we conducted a series of ANOVAs with group (NCC; CC; EP) as the

22 independent variable and the NEO-FFI-R subscales (Extraversion; Neuroticism; Openness;

23 Agreeableness and Conscientiousness) as the dependent variables. The CC and EP groups both

24 reported significantly higher scores on the Neuroticism and Openness subscales compared to 
1 NCC $(p<.001)$. The EP population also reported significantly higher scores on the Neuroticism

2 subscale compared to the CC (and NCC groups). The non-creative control group was

3 significantly more Conscientious than the early psychosis group $(p<.05)$.

4

[Insert Table 2 near here]

$7 \quad$ Group Differences on the O-LIFE

8 Whereas the NEO-FFI-R is a measure of "normal" personality features, the O-LIFE measures

9 schizotypal personality traits. Results of the one-way ANOVA comparing the three groups on the

10 O-LIFE subscales are presented in Table 3. These show the EP and CC participants scored

11 significantly higher on Unusual Experiences (UE), Impulsive Non-Conformity (Imp N), and

12 Cognitive Disorganisation (Cog D) compared to the NCC participants (all $p<.001)$, but were not

13 significantly different from each other. In relation to Introverted Anhedonia (IA), although the

14 ANOVA just met statistical significance, none of the post-hoc tests were significantly different

15 from each other. This casts doubt on the reliability of the omnibus test; hence we have not

16 included this variable among the group of significantly different group comparisons.

18 Considering NEO and O’LIFE together, Openness, Impulsive Non-Conformity, Unusual

19 Experiences and Cognitive Disorganisation are similarly associated with EP and CC populations.

20 Results on the Neuroticism personality factor in the NEO_FFI_R present a slightly different

21 picture. Similar to the above factors, both clinical and creative participants recorded

22 significantly higher scores on Neuroticism when compared to the NCC group, however the EP

23 sample recorded significantly higher results again when compared to the $\mathrm{CC}$ group. 
Hypothesis 2: Negative personality features such as paranoia and suspiciousness will be

3 more evident in EP participants, when compared to CC, NCC participants.

4

5

6 Group Differences on the $P / S Q$

7 The P/SQ measures negative personality feature such as general suspiciousness and hostility in

8 interpersonal communication, alongside mistrustful and wary tendencies and resentment toward

9 perceived hardship. To test the hypothesis that there would be a difference in positive and

10 negative schizotypal features between EP, CC and NCC groups, a one-way ANOVA was

11 conducted on P/SQ scores (see Table 4). The overall paranoia/suspiciousness mean score was

12 significantly higher in the EP and CC groups compared to the NCC $(p<.001)$, however a

13 significant difference $(\mathrm{p}<.001)$ was also recorded between the EP and CC groups, supporting our

14 hypothesis that negative schizotypal personality characteristics, measured by the PSQ, will be

15 more prevalent in the EP population. Within the subscale comparisons, a comparative pattern of

16 results was found for the Interpersonal Suspiciousness domain, with the NCC group reporting

17 significantly lower scores than the other two groups $(p<.001)$. The EP participants reported

18 significantly greater negative personality features on Negative Mood and Anger Impulsiveness

19 compared to the NCC participants $(p<.001)$, however they were not significantly elevated

20 compared to the CC group. Finally, scores on the Hardship/Resentment subscale were

21 significantly higher among the EP group compared to both the CC and NCC groups.

[Insert Table 4 near here] 
1 To summarize, this cluster of shared personality features indicates adaptive character traits

2 typically associated with positive schizotypal features that were found with both EP and CC

3 populations. However, the EP population is distinguished from the CC both by an increase in

4 Neuroticism and Interpersonal Suspiciousness symptoms, and the presence of additional negative

5 schizotypal features. The presence and intensity of these negative traits may either impede

6 creativity or prevent this creative potential converting to creative achievement in the EP

7 population.

[Insert Figure 1 near here]

Hypothesis 3: The CC and EP participants will record significantly higher divergent

11 thinking (creative potential) scores compared to NCC participants, but CC participants

12 will record significantly higher levels of creative achievement when compared to both NCC

13 and EP individuals.

15 Group Differences of the Abbreviated Torrance Test for Adults (ATTA) (Goff, 2002) and

16 Creative Achievement Questionnaire (CAQ) (Carson, 2005).

18 A series of one-way ANOVAs were conducted to determine if there were any group differences

19 in creative potential as measured by the divergent thinking (ATTA measure) and in creative

20 achievement as measured by the CAQ (see Table 5). Not surprisingly the CC individuals scored

21 significantly higher on the divergent thinking and CAQ measures, compared to the NCC group.

22 While there was no significant difference between the CC and EP population on the divergent

23 thinking task, there was a significant difference between CC and EP on the CAQ. Of particular

24 note however is the finding that the EP population scored significantly higher than the NCC on 
1 the CAQ. These results suggest that while the EP population has similar creative potential

2 (divergent thinking) to the creative population, they are less able to translate this into creative

3 achievement. However, some creative achievement was still evident.

[Insert Table 5 near here]

6 Discussion

7

8 This research aimed to delineate the similarities and differences in personality between highly

9 creative and early psychosis populations, using a non-creative but similarly intellectually capable

10 control group. Before discussing the results it is important to note that as our research was cross

11 sectional rather than longitudinal and so our comments are preliminary in nature. These results

12 support previous assertions that the personality and schizotypal traits of highly creative

13 individuals are more closely aligned with clinical patients than the normal population (Claridge

$14 \&$ Blakey, 2009; Strong et al., 2007). Furthermore, these results lend additional support to the

15 widely held view that both affect (Neuroticism) and aspects of cognitive flexibility (Openness)

16 contribute to creativity (Richards, 2001; Rybakowski et al., 2008; Srivastava et al., 2010; Strong

17 et al., 2007). Both creative and clinical populations share personality traits that are exploratory,

18 seek new experiences, are non-conformist, and prone to challenge social norms. Furthermore,

19 both demonstrate a propensity for disorganised thinking, emotional sensitivity and general

20 interpersonal suspiciousness.

22 There are of course a range of biological, social and motivational inhibitors to the psychosis

23 population not achieving the creative output that their creativity scores in this study would

24 suggest they have the capacity for (Richards, 2001). However, one additional difference 
1 between the two populations suggested by these data may lie in the ability to regulate heightened

2 emotions for the purposes of maintaining social connectedness. On the one hand, emotional

3 intensity is required for creative expression (Feist, 2006) while on the other hand self

4 management of emotions are needed in collaborative social interactions necessary for creative

5 achievement. Czikszentmihalyi (1999) hypothesised that an individual's ability to achieve

6 creatively involves not simply the ability to produce outstanding creative products, but

7 implicates personality traits that enable access to a network of contacts and highly developed

8 interpersonal skills that make it possible for the creative product to have influence. The high

9 functioning creative individual may have the ability to sufficiently regulate their sensitivity in the

10 social relationships necessary for creative influence. The model below (Figure 2) summarises

11 these results.

15 Nevertheless, limited creative achievement is possible for psychosis patients, as evidenced by the

16 early psychosis group's significantly higher scores on creative achievement compared to non-

17 creative controls. This suggests that those with early psychosis have a capacity for creative

18 achievement. It may be in part that psychosis patients' elevated emotional sensitivity,

19 suspiciousness and defensiveness impedes their ability to effectively communicate and

20 collaborate with others within their creative network. Elevated emotional sensitivity is of

21 particular relevance in creative achievement as rejection (of creative work) is an associated

22 aspect of a creative vocation (Van den Eynde, Fisher, \& Sonn, 2015). Mature creative artists

23 learn to manage this rejection (Czikszentmihalyi, 1999), however, this may be difficult for the

24 equally talented but emotionally vulnerable early psychosis individual. Difficulties with 
1 managing this type of rejection inherent in creative industries is likely to have a reciprocal

2 relationship with the characteristics of hypersensitivity, suspiciousness and defensiveness found

3 in this study.

4

5 This may prove to be a new avenue for intervention for early psychosis patients; in that early

6 psychosis patients with proven creative ability may benefit from interventions aimed at

7 enhancing communication skills and building resilience in the face of rejection. This in turn may

8 increase their ability to maintain creative networks and improve vocational outcome. Therefore

9 through research, which focuses on creative outcomes for early psychosis populations, rather

10 than cognitive deficits, it may lead to an associated reduction in stigma for this population

11 (Serafini et al., 2011).

13 Limitations

14 Our findings are limited by the relatively small sample size and by the cross-sectional nature of

15 the research. Moreover the challenge of defining a creative and early psychosis sample has been

16 articulated by other researchers (Breitborde, Srihari, \& Woods, 2009; Kaufman, 2009; MacCabe

17 et al., 2018). While we have sought to address these issues, the ongoing discourse in determining

18 operational definitions for these populations remains a concern for researchers in the field. The

19 lack of clarification in defining these populations contributes to difficulty in comparing studies

20 and therefore is a limiting factor for the current research. Further research to elucidate these

21 differences will be important future area of investigation.

22

\section{Conclusion and implications}


1 Our findings support the need for further targeted longitudinal research into young, at risk,

2 creative populations and early psychosis patients (McGorry, 2009). In particular our results

3 underscore the need to research and develop programmes to foster and strengthen resilient,

4 personality features in young, vulnerable, creative populations. These programmes would

5 promote emotional self-management, along with interpersonal skills to challenge negative,

6 suspicious patterns of thinking and behaviour.

7

8 Finally, the current results provide additional support for the development of preventative

9 treatment protocols for creative populations, consistent with other recent studies that have

10 identified the unique psychological vulnerability of creative populations (Gostoli, Cerini,

11 Piolanti, \& Rafanelli, 2017; Van den Eynde et al., 2015). The recent McCabe epidemiological

12 study (MacCabe et al., 2018) provides additional compelling support for this assertion as they

13 conclude that, artistic creativity is a risk factor for mental illness which is analogous to other

14 well documented risk factors for psychosis.

15

16 Conflict of interest

17 The authors have no conflict of interest to declare.

\section{Acknowledgements}

21 The authors would like to acknowledge Shannon Gostelow and Nicole O'Reilly who were

22 research assistants for the project and Rob Brockman for his contribution to the research. The

23 authors would also like to acknowledge the National Health and Medical Research Council

24 (NHMRC) Project grant (APP630471), and the Australian Research Council (ARC) Future 
1 Fellowship (FT0991511) both grants held by Melissa J Green (UNSW). Melissa J Green was

2 responsible for this project as executed at UNSW and is affiliated with UNSW, Neuroscience

3 Research Australia (NeuRA), the Black Dog Institute, and the Macquarie Centre for Excellence

4 in Cognition and its Disorders.

5

6

7

8

9

10

11

12

13

14

15

16

17

18

19

20

21

22

23

24

25

26

27

28

29

30

31

32

33

Ando, V., Claridge, G., \& Clark, K. (2014). Psychotic traits in comedians. The British Journal of Psychiatry. doi:10.1192/bjp.bp.113.134569

Andreasen, N. C. (1987). Creativity and mental illness: prevalence rates in writers and their firstdegree relatives. The American journal of psychiatry, 144(10), 1288-1292.

Batey, M., \& Furnham, A. (2008). The relationship between measures of creativity and schizotypy. Personality and Individual Differences, 45(8), 816-821. doi:10.1016/j.paid.2008.08.014

Breitborde, N. J. K., Srihari, V. H., \& Woods, S. W. (2009). Review of the operational definition for first-episode psychosiseip. Early intervention in psychiatry, 3(4), 259-265. doi:10.1111/j.1751-7893.2009.00148.x

Brod, J. (1997). Creativity and Schizotypy In G. Claridge (Ed.), Schizotypy: Implications for illness and health (pp. 274-298). London: Oxford University Press.

Burch, G. S. J., Pavelis, C., Hemsley, D. R., \& Corr, P. J. (2006). Schizotypy and creativity in visual artists. British Journal of Psychology, 97(2), 177-190. doi: $10.1348 / 000712605 \times 60030$

Carrión, R. E., Walder, D. J., Auther, A. M., McLaughlin, D., Zyla, H. O., Adelsheim, S., . . Cornblatt, B. A. (2018). From the psychosis prodrome to the first-episode of psychosis: No evidence of a cognitive decline. Journal of Psychiatric Research, 96, 231-238. doi:https://doi.org/10.1016/j.jpsychires.2017.10.014 
Carson, S. H. (2011). Creativity and psychopathology: A Shared Vulnerability Model. Canadian JOurnal of Psychiatry, 56(3), 144-154.

Carson, S. H., Peterson, J. B., \& Higgins, D. M. (2005). Reliability, Validity, and Factor Structure of the Creative Achievement Questionnaire. Creativity Research Journal, 17(1), 37-50. doi:10.1207/s15326934crj1701_4

Claridge, G., \& Blakey, S. (2009). Schizotypy and affective temperament: Relationships with divergent thinking and creativity styles. Personality and Individual Differences, 46(8), 820-826.

Cloninger, R. (1994). The temperament and character inventory (TCI): A guide to its development and use. St Louis, MO. Washington University: Centre for Psychobiology of Personality.

Cochrane, M., Petch, I., \& Pickering, A. D. (2010). Do measures of schizotypal personality provide non-clinical analogues of schizophrenic symptomatology? Psychiatry Research, 176(2), 150-154. doi:10.1016/j.psychres.2009.01.031

Cochrane, M., Petch, I., \& Pickering, A. D. (2012). Aspects of cognitive functioning in schizotypy and schizophrenia: Evidence for a continuum model. Psychiatry Research, 196(2-3), 230-234. doi:10.1016/j.psychres.2012.02.010

Costa, J., P.T., \& McCrae, R. R. (1985). The NEO Personality Inventory Manual. from Psychological Assessment Resources

Czikszentmihalyi, M. (1999). Implications of a Systems Perspective for the Study of Creativity. New York, N.Y.: Cambridge University Press.

Erdfelder, E., Faul, F., \& Buchner, A. (1996). GPOWER: A general power analysis program. . Behavior research methods, instruments, \& computers, 28(1), 1-11.

Feist, G. (2006). The influence of personality on artistic and scientific creativity. In R. J. Sternberg (Ed.), Handbook of Creativity (pp. 273-312). New York: Cambridge University Press.

Fusar-Poli, P., Tantardini, M., De Simone, S., Ramella-Cravaro, V., Oliver, D., Kingdon, J., . . . McGuire, P. Deconstructing vulnerability for psychosis: Meta-analysis of environmental risk factors for psychosis in subjects at ultra high-risk. European Psychiatry, 40, 65-75. doi:10.1016/j.eurpsy.2016.09.003

Goff, K., \& Torrance, E. P. (2002). Abbreviated Torrance Test for Adults (ATTA).

Gostoli, S., Cerini, V., Piolanti, A., \& Rafanelli, C. (2017). Creativity, Bipolar Disorder Vulnerability and Psychological Well-Being: A Preliminary Study. Creativity Research Journal, 29(1), 63-70. doi:10.1080/10400419.2017.1263511

Jamison, K. R. (1995). Manic-depressive illness and creativity. Sci Am, 272(2), 62-67.

Jung, R. E., Grazioplene, R., Caprihan, A., Chavez, R. S., \& Haier, R. J. (2010). White Matter Integrity, Creativity, and Psychopathology: Disentangling Constructs with Diffusion Tensor Imaging. PLoS ONE [Electronic Resource], 5(3). doi:org/10.1371/journal.pone.0009818

Jung, R. E., Mead, B. S., Carrasco, J., \& Flores, R. A. (2013). The structure of creative cognition in the human brain. Frontiers in Human Neuroscience, 7. doi:10.3389/fnhum.2013.00330

Kaufman, J. C. a. B., Ronald A. (2009). Beyond Big and Little: The Four C Model of Creativity. Review of General Psychology, 13, 1-12.

Kay, S. R., Fiszbein, A., \& Opler, L. A. (1987). The Positive and Negative Symptom Scale (PANSS) for Schizophrenia. Schizophrenia Bulletin, 13, 261-276. 
Kessler, R. C., Amminger, G. P., Aguilar-Gaxiola, S., Alonso, J., Lee, S., \& Ustun, T. B. (2007). Age of onset of mental disorders: A review of recent literature. Current opinion in psychiatry, 20(4), 359-364. doi:10.1097/YCO.0b013e32816ebc8c

Kyaga, S., Lichtenstein, P., Boman, M., Hultman, C., Langstrom, N., \& Landen, M. (2011). Creativity and mental disorder: family study of 300,000 people with severe mental disorder. British Journal of Psychiatry, 199, 373-379.

Lecrubier, Y., Sheehan, D. V., Weiller, E., Amorim, P., Bonora, I., Harnett Sheehan, K., . . . Dunbar, G. C. The Mini International Neuropsychiatric Interview (MINI). A short diagnostic structured interview: reliability and validity according to the CIDI. European Psychiatry, 12(5), 224-231. doi:10.1016/S0924-9338(97)83296-8

Lichtenstein, P., Yip, B. H., Björk, C., Pawitan, Y., Cannon, T. D., \& Sullivan, P. (2009). Common genetic determinants of schizophrenia and bipolar disorder in Swedish families: a population-based study. The Lancet, Jan 17-23(373), 9659.

Ma, H.-H. (2009). The effect size of variables associated with creativity: a meta-analysis. Creativity Research Journal, 21(1), 30-42. doi:10.1080/10400410802633400

MacCabe, J. H., Sariaslan, A., Almqvist, C., Lichtenstein, P., Larsson, H., \& Kyaga, S. (2018). Artistic creativity and risk for schizophrenia, bipolar disorder and unipolar depression: a Swedish population-based case-control study and sib-pair analysis. The British Journal of Psychiatry, 212(6), 370-376. doi:10.1192/bjp.2018.23

Masillo, A., R., V. L., Riccardo, S., Martina, B., Nella, L. C., Ludovica, T., . . Paolo, F. N. (2017). Interpersonal sensitivity, bullying victimization and paranoid ideation among help-seeking adolescents and young adults. Early intervention in psychiatry, $0(0)$. doi:doi:10.1111/eip.12447

Mason, O. (2015). The Assessment of Schizotypy and Its Clinical Relevance. Schizophrenia Bulletin, 41(Suppl 2), S374-S385. doi:10.1093/schbul/sbu194

Mason, O., \& Claridge, G. (2006). The Oxford-Liverpool Inventory of Feelings and Experiences (O-LIFE): further description and extended norms. Schizophrenia Research, 82(2-3), 203-211. doi:10.1016/j.schres.2005.12.845

Mc Crae, R. P., \& Costa, J., P.T. (2004). A contemplated revision of the NEO Five-Factor Inventory. Personality \& Individual Differences, 36, 587-596.

McGorry, P., Killackey, Eoin, Yung, Alison, R. (2009). Early Intervention in Psychotic Disorders: detection and treatment of the first episode and the critical early stages. Medical Journal of Australia, 187(7), S8.

Nelson, B., \& Rawlings, D. (2010). Relating Schizotypy and Personality to the Phenomenology of Creativity. Schizophrenia Bulletin, 36(2), 388-399. doi:10.1093/schbul/sbn098

Nettle, D. (2006). Schizotypy and mental health amongst poets, visual artists, and mathematicians. Journal of Research in Personality, 40(6), 876-890. doi:10.1016/j.jrp.2005.09.004

Nowakowska, C., Strong, C. M., Santosa, C. M., Wang, P. W., \& Ketter, T. A. (2005). Temperamental commonalities and differences in euthymic mood disorder patients, creative controls, and healthy controls. Journal of affective disorders, 85(1-2), 207-215. doi:10.1016/j.jad.2003.11.012

Power, R. A., Steinberg, S., Bjornsdottir, G., Rietveld, C. A., Abdellaoui, A., Nivard, M. M., .. . Stefansson, K. (2015). Polygenic risk scores for schizophrenia and bipolar disorder predict creativity. Nature Neuroscience, 18(7), 953-955. doi:10.1038/nn.4040 
Rawlings, D., \& Freeman, J. L. (1996). A questionnaire for the measurement of paranoia/suspiciousness. British Journal of Clinical Psychology, 35(3), 451-461. doi:10.1111/j.2044-8260.1996.tb01199.x

Rawlings, D., \& Freeman, J. L. (1997). Measuring paranoia/suspiciousness. In G. Claridge (Ed.), Schizotypy: Implications for illness and health. (pp. 38-60). Oxford, England UK: Oxford University Press.

Richards, R. (2001). Creativity and the Schizophrenia spectrum: more and more interesting. Creativity Research Journal, 13(1), 111-132.

Rowland, J. E., Hamilton, M. K., Vella, N., Lino, B. J., Mitchell, P. B., \& Green, M. J. (2012). Adaptive associations between social cognition and emotion regulation are absent in schizophrenia and bipolar disorder. Frontiers in Psychology, 3, 607. doi:org/10.3389/fpsyg.2012.00607

Ryan, J. J., Carruthers, C. A., Miller, L. J., Souheaver, G. T., Gontkovsky, S. T., \& Zehr, M. D. (2003). Exploratory factor analysis of the Wechsler Abbreviated Scale of Intelligence (WASI) in adult standardization and clinical samples. Applied Neuropsychology, 10(4), 252-256.

Rybakowski, J. K., Klonowska, P., Parrzala, A., \& Jaracz, J. (2008). Psychopathology and creativity. Archives of Psychiatry and Psychotherapy, 1(1), 37 - 47.

Sass, L. A. (2001). Schizophrenia, Modernism, and the "Creative Imagination": On Creativity and Psychopathology. Creativity Research Journal, 13(1), 55-74. doi:10.1207/s15326934crj1301_7

Serafini, G., Pompili, M., Haghighat, R., Pucci, D., Pastina, M., Lester, D., . . Girardi, P. (2011). Stigmatization of schzophtrenia as perceived by nurses, medical doctors, medical students and patients. Journal of Psychiatric and Mental Health Nursing, 18, 576-585.

Siddi, S., Petretto, D. A., \& Preti, A. (2017). Neuropsychological correlates of schizotypy: a systematic review and meta-analysis of cross-sectional studies. Cognitive Neuropsychiatry, 22(3), 186-212. doi:10.1080/13546805.2017.1299702

Srivastava, S., Childers, M. E., Baek, J. H., Strong, C. M., Hill, S. J., Warsett, K. S., . . Ketter, T. A. (2010). Toward interaction of affective and cognitive contributors to creativity in bipolar disorders: A controlled study. Journal of affective disorders, 125(1-3), 27-34. doi:10.1016/j.jad.2009.12.018

Strong, C. M., Nowakowska, C., Santosa, C. M., Wang, P. W., Kraemer, H. C., \& Ketter, T. A. (2007). Temperament-creativity relationships in mood disorder patients, healthy controls and highly creative individuals. Journal of affective disorders, 100(1-3), 41-48. doi:10.1016/j.jad.2006.10.015

Tabachnick, B. G., Fidell, L. S., \& Osterlind, S. J. (2001). Using multivariate statistics.

Torrance, E. P. (2000). Research review for the Torrance tests of creative thinking: Figural and verbal forms $a$ and $b$. Bensenville, Illinois: Scholastic Testing Service, Inc.

Valmaggia, L. R., Day, F. L., Kroll, J., Laing, J., Byrne, M., Fusar-Poli, P., \& McGuire, P. (2015). Bullying victimisation and paranoid ideation in people at ultra high risk for psychosis. Schizophrenia Research, 168(1), 68-73. doi:https://doi.org/10.1016/j.schres.2015.08.029

Van den Eynde, j., Fisher, A., \& Sonn, C. (2015). Pride, passion and pitfalls: working in the Australian Entertainment Industry: Phase Two. Victoria University.

Wang, L., Xu, X., Wang, Q., Healey, G., Su, L., \& Pang, W. (2017). Are Individuals with Schizophrenia or Schizotypy More Creative? Evidence from Multiple Tests of Creative 
Potential. Creativity Research Journal, 29(2), 145-156.

2 doi:10.1080/10400419.2017.1302777

3 Wechsler, D., \& Zhou, X. (2011). Manual for the Wechsler Abbreviated Scale of Intelligence. 4 Bloomington, MN: Pearson Executive Office.

5 Yaghoubi H, \& A., M. (2012). Validation of the Oxford- Liverpool inventory of feelings and 6 experiences (O-LIFE) questionnaire. Zahedan J Res Med Sci (ZJRMS), 14(9), 24-29. 


\section{Table 1.}

Sample description

\begin{tabular}{lllll}
\hline & EP & CC & NCC & $\begin{array}{l}\text { Statistical Value for } \\
\text { main effect }\end{array}$ \\
\hline$N$ & 21 & 55 & 24 & \\
Age & $25.4 \pm 4.2$ & $23.4 \pm 4.3$ & $22.8 \pm 3.6$ & $\left(\mathrm{~F}_{2,101}=2.433, \mathrm{p}=.093\right)$ \\
Female $(\%)$ & 57.1 & 63.6 & 62.5 & $\left(\chi^{2}=0.201, \mathrm{p}=.904\right)$ \\
IQ & $107.9 \pm 15.2$ & $109.4 \pm 10.3$ & $104.9 \pm 13.4$ & $\left(\mathrm{~F}_{2,97=1.101, \mathrm{p}=.337)}\right.$ \\
\hline
\end{tabular}




\section{Table 2}

Means and standard deviations for all groups on the NEO variables

\begin{tabular}{lcccl}
\hline & EP & CC & NCC & \multicolumn{1}{c}{ Statistical values for main effects } \\
\hline$N$ & 21 & 55 & 24 & \\
Neuroticism & $30.4 \pm 8.6$ & $24.6 \pm 8.3$ & $17.0 \pm 6.9$ & $\mathrm{~F}_{2,99}=15.90, \mathrm{p}<.001^{\mathrm{a}}$ \\
Extraversion & $29.3 \pm 7.9$ & $30.3 \pm 6.4$ & $29.2 \pm 4.8$ & $\mathrm{~F}_{2,99}=.346, \mathrm{p}=.709$ \\
Openness & $33.9 \pm 7.2$ & $33.4 \pm 6.8$ & $24.2 \pm 5.8$ & $\mathrm{~F}_{2,99}=17.90, \mathrm{p}<.001^{\mathrm{b}}$ \\
Agreeableness & $28.1 \pm 5.3$ & $31.7 \pm 7.1$ & $31.0 \pm 5.9$ & $\mathrm{~F}_{2,99}=2.45, \mathrm{p}=.091$ \\
Conscientiousness & $26.8 \pm 7.5$ & $29.7 \pm 6.9$ & $32.4 \pm 7.3$ & $\mathrm{~F}_{2,99}=3.45, \mathrm{p}<.05^{\mathrm{c}}$ \\
\hline
\end{tabular}

$\mathrm{a}=\mathrm{EP}>\mathrm{CC}>\mathrm{NCC}^{* *}$

$\mathrm{b}=\mathrm{EP}, \mathrm{CC}>\mathrm{NCC}^{* *}$

$\mathrm{c}=\mathrm{NCC}>\mathrm{EP}^{*}$

$* * \mathrm{p}<.01, * \mathrm{p}<.05$.

\section{Table 3}


Means and standard deviations for all groups on the O-LIFE variables

\begin{tabular}{lcccl}
\hline & EP & CC & NCC & Statistical values for main effects \\
\hline$N$ & 21 & 55 & 23 & \\
Unusual Experiences & $12.4 \pm 7.6$ & $13.3 \pm 6.4$ & $3.4 \pm 4.0$ & $F_{2,98}=20.89, \mathrm{p}<.001^{\text {a }}$ \\
Cognitive Disorganisation & $14.8 \pm 5.1$ & $12.3 \pm 5.0$ & $5.7 \pm 5.1$ & $F_{2,98}=19.96, \mathrm{p}<.001^{\text {a }}$ \\
Introverted Anhedonia & $8.2 \pm 5.3$ & $5.6 \pm 3.9$ & $7.6 \pm 5.0$ & $F_{2,96}=3.30, \mathrm{p}=.042$ \\
Impulsive Nonconformity & $9.6 \pm 4.9$ & $9.4 \pm 4.0$ & $5.1 \pm 3.3$ & $F_{2,98}=10.05, \mathrm{p}<.001^{\text {a }}$ \\
\hline
\end{tabular}

$\mathrm{a}=\mathrm{EP}, \mathrm{CC}>\mathrm{NCC}^{* *}$

$* * \mathrm{p}<.01$

\section{Table 4}

Means and standard deviations for all groups on the PSQ variable 


\begin{tabular}{|c|c|c|c|c|}
\hline & EP & $\mathrm{CC}$ & $\mathrm{NCC}$ & Statistical values for main effects \\
\hline$N$ & 21 & 56 & 23 & \\
\hline Total paranoia/suspicious & $24.9 \pm 9.2$ & $19.1 \pm 7.9$ & $14.2 \pm 7.2$ & $\mathrm{~F}_{2,99}=9.83, \mathrm{p}<.001^{\mathrm{a}}$ \\
\hline Interpersonal suspicious & $6.6 \pm 3.4$ & $5.5 \pm 2.7$ & $3.1 \pm 2.6$ & $\mathrm{~F}_{2,99}=9.18, \mathrm{p}<.001^{\mathrm{b}, \mathrm{c}}$ \\
\hline Negative mood & $4.5 \pm 1.7$ & $3.7 \pm 1.6$ & $2.8 \pm 1.2$ & $\mathrm{~F}_{2,99}=6.33, \mathrm{p}<.05^{\mathrm{d}}$ \\
\hline Anger impulsiveness & $4.3 \pm 3.2$ & $3.3 \pm 1.7$ & $2.3 \pm 1.2$ & $\mathrm{~F}_{2,99}=5.36, \mathrm{p}<.05^{\mathrm{d}}$ \\
\hline Mistrust Wariness & $3.6 \pm 2.0$ & $2.8 \pm 1.9$ & $2.6 \pm 1.9$ & $\mathrm{~F}_{2,99}=1.76, \mathrm{p}=.176$ \\
\hline Hardship & $3.5 \pm 2.2 \mathrm{e}$ & $2.1 \pm 2.1$ & $1.7 \pm 1.5$ & $\mathrm{~F}_{2,99}=5.36, \mathrm{p}<.05^{\mathrm{e}}$ \\
\hline $\begin{array}{l}\mathrm{a}=\mathrm{EP}>\mathrm{CC}>\mathrm{NCC}^{* *} \\
\mathrm{~b}=\mathrm{EP}>\mathrm{NCC}^{* *} \\
\mathrm{c}=\mathrm{CC}>\mathrm{NCC}^{*} \\
\mathrm{~d}=\mathrm{EP}>\mathrm{NCC} * \\
\mathrm{e}=\mathrm{EP}>\mathrm{CC}, \mathrm{NCC}^{*} \\
* * \mathrm{p}<.01 .{ }^{*} \mathrm{p}<.05\end{array}$ & & & & \\
\hline
\end{tabular}

\section{Table 5}

Means and standard deviation for all groups on creative achievement (CAQ) and creative thinking (ATTA) 


\begin{tabular}{lcccl}
\hline & EP & CC & NCC & Statistical values for main effects \\
\hline$N$ & 21 & 54 & 23 & \\
Creative Achievement & $25.1 \pm 25.6$ & $48.2 \pm 29.4$ & $3.4 \pm 4.7$ & $\mathrm{~F}_{(2,97)}=27.11 . \mathrm{p}<.001^{\mathrm{a}, \mathrm{b}}$ \\
Creative Thinking & $76.5 \pm 12.5$ & $79.7 \pm 8.8$ & $67.5 \pm 9.2$ & $\mathrm{~F}_{(2,97)}=12.68, \mathrm{p}<.001^{\mathrm{b}, \mathrm{c}}$ \\
\hline
\end{tabular}

$\mathrm{a}=\mathrm{CC}>\mathrm{EP}, \mathrm{NCC}^{* *}$

$\mathrm{b}=\mathrm{EP}>\mathrm{NCC}^{*}$

$\mathrm{c}=\mathrm{CC}>\mathrm{NCC}^{* *}$

$* * \mathrm{p}<.01, * \mathrm{p}<.05$. 


\section{Figure 1.}

Graph of means for NEO-FFI-R (Neuroticism, Openness), O-LIFE (Unusual Experiences, Impulsive Non-Conformity, Cognitive Disorganization) and Paranoid Suspiciousness Questionnaire (Total score).

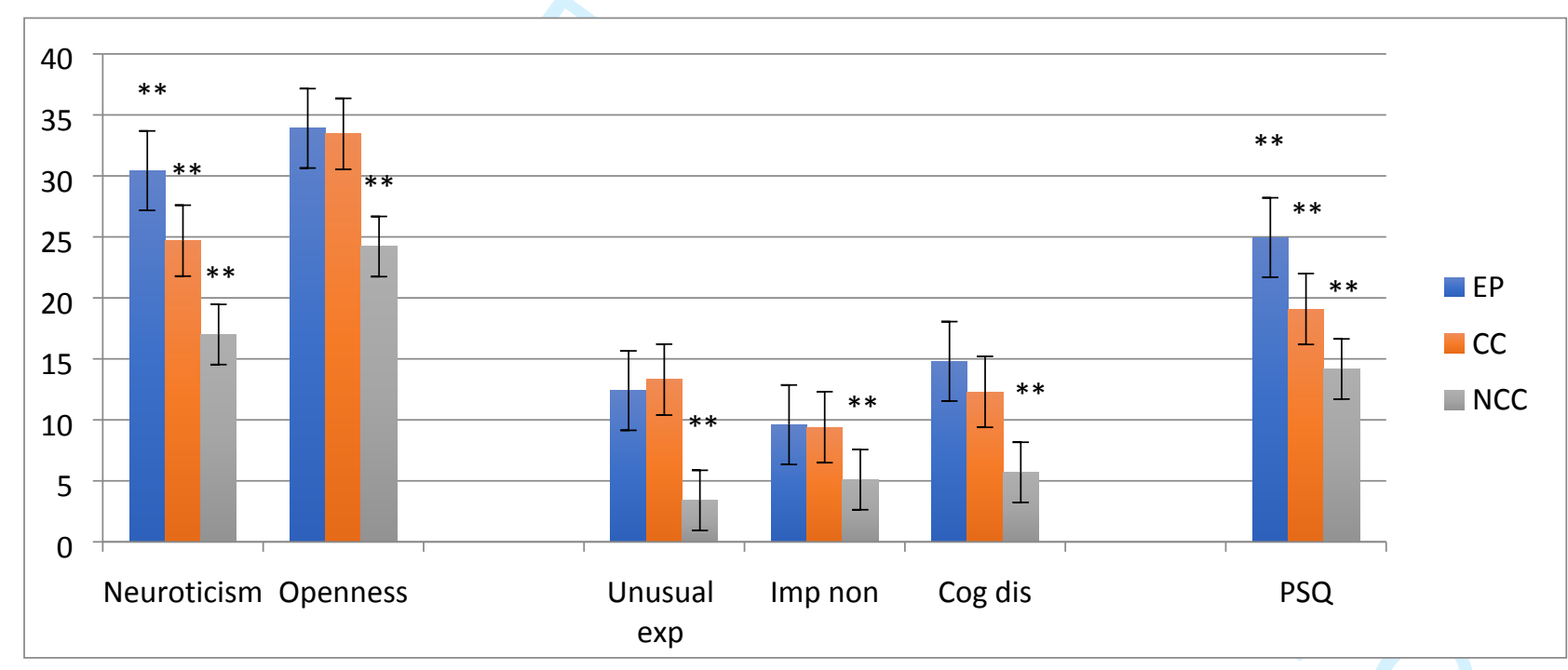

$* * p<.01$ 


\section{Figure 2.}

A model of shared and distinct personality and schizotypal traits mapped to CC and EP populations

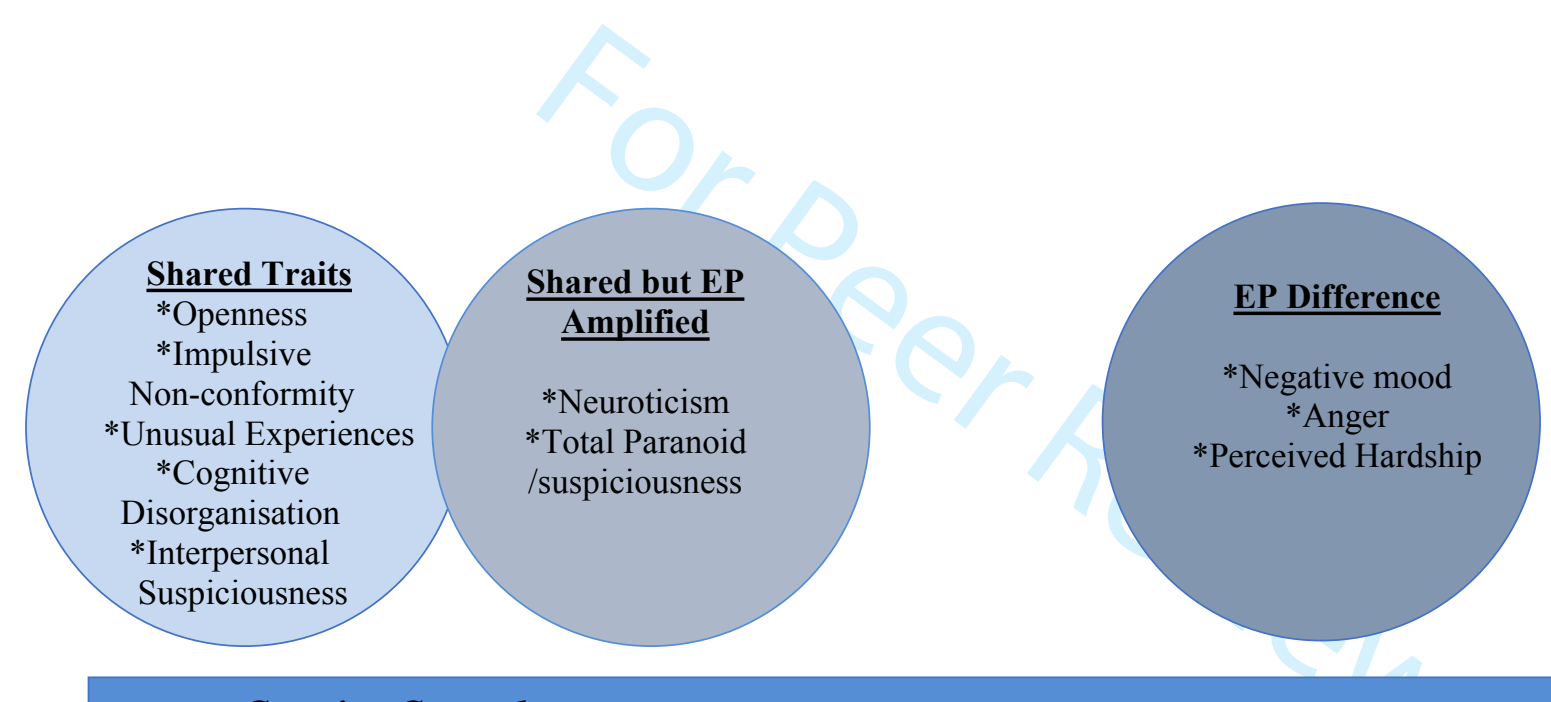

Creative Control

Early Psychosis group 